\title{
Effect of Nd on Microstructure and Mechanical Properties of AZ31 Magnesium Alloy
}

\author{
Li Mingzhao, Li Cong, Liu Xuguang, Xu Bingshe
}

Key Laboratory of Interface Science and Engineering in Advanced Materials of Taiyuan University of Technology, Ministry of Education, Taiyuan University of Technology, Taiyuan 030024, China

\begin{abstract}
Effect of Nd on as-cast microstructure and mechanical properties of AZ31 magnesium alloy were investigated by ICP, metallographic microscopy, SEM, EDS, XRD and mechanical measurement. The results show that the microcontent of Nd added in AZ31 alloy could result in the formation of intermetallic compounds of $\mathrm{Al}_{2} \mathrm{Nd}$ and $\mathrm{Mg}_{12} \mathrm{Nd}$ at grain boundary and in $\alpha-\mathrm{Mg}$ matrix, and the absorption rate of $\mathrm{Nd}$ reached $95 \%$, which obviously refined AZ31 alloy microstructure and further improved mechanical properties. The AZ31 alloy containing Nd showed a tensile strength of $245 \mathrm{MPa}$, a yield strength of $171 \mathrm{MPa}$ and a elongation of $9 \%$.
\end{abstract}

Key Words: magnesium alloy; Nd(neodymium); microstructure; mechanical property

\begin{abstract}
Magnesium alloy has been widely applied in various fields as one of the lightest structure materials because of its good performances $^{[1]}$. AZ31 is a wrought magnesium alloy that is widely applied for its excellent deforming property and satisfactory comprehensive property. However, the contents of alloy elements in AZ31 are low, its efficiencies of solution strengthening and aging strengthening are not so obvious, and the mechanical properties at room temperature are poor. These disadvantages restrict to a certain extent the further development and broad application of AZ31 alloy ${ }^{[2]}$. Generally, the study of AZ31 magnesium alloy is mainly focused on its hot deformation occurring in the processes such as extrusion, rolling and forging ${ }^{[3]}$. There are only few works concerning the improvement of the microstructure and mechanical property of AZ31 magnesium alloy ${ }^{[4]}$. Rare earth element $\mathrm{Nd}$ is a good strengthening element for magnesium alloy ${ }^{[5]}$, but the investigation of the effect of $\mathrm{Nd}$ on AZ31 alloy is lack. This study will be focused on the effects of $\mathrm{Nd}$ on the as-cast microstructure and mechanical properties of AZ31 based alloys, which provide basic data for the plastic deformation of as-cast microstructure in alloy.
\end{abstract}

\section{Experimental}

The AZ31 alloy containing Nd was prepared by melting and casting commercial AZ31 magnesium alloy together with $\mathrm{Mg}-20 \mathrm{wt} \% \mathrm{Nd}$ alloy in a vacuum resistor furnace. The amount of $\mathrm{Nd}$ added into AZ31 magnesium alloy was $0.6 \mathrm{wt} \%$. The experiment procedure was based on the following steps. Firstly, a mould was preheated at $473 \mathrm{~K}$, and AZ31 alloy was put in a crucible after weighed. Secondly, both the preheated mould and that in crucible were placed into the furnace and then the furnace was vacuumized. When the vacuum level reached $10^{-2} \mathrm{~Pa}$, the high vacuum value was closed and Ar gas was used to purge the system in order to prevent magnesium from oxidation. The vacuum-pumping was repeated. Thirdly, AZ31 alloy was heated up to $993 \mathrm{~K}$ under Ar gas protection and then $\mathrm{Mg}-\mathrm{Nd}$ alloy was introduced. The melt was stirred to assist the dissolution of the master alloy. Finally, the melt was held at $993 \mathrm{~K}$ for a while, and then was poured into a bar-shaped mould.

Alloy samples were taken from different points of bar-shaped castings, and then polished and etched for

$\overline{\text { Received date: May 30, } 2008}$

Foundation item: National Basic Research Priorities Program of China (90306014) and Key Laboratory Foundation of Shanxi Province (2007031014)

Biography: Li Mingzhao, Ph.D., Associate Professor, College of Materials Science and Engineering, Taiyuan University of Technology, Taiyuan 030024, Tel: 0086-351-6010311. 
characterization and analysis. The content of trace elements was determined using inductive coupled plasma atomic emission spectrometry (ICP). The microstructure was observed with metallographic microscope and scanning electron microscope (SEM), the phases of samples was detected with X-ray diffraction instrument, and the mechanical properties were measured on WDW-100KN draw-bench.

\section{Results and discussion}

\subsection{Change of alloy composition}

The contents of $\mathrm{Nd}$ in the samples are shown in Table 1, in which the samples 1-1,1-2 and 1-3 are referred to adding no $\mathrm{Nd}$, and the samples 2-1, 2-2 and 2-3 are referred to adding $\mathrm{Nd}$. It can be seen that $\mathrm{Nd}$ content in Sample 2 was reduced from $0.6 \%$ to $0.57 \%$, showing that the absorption rate of $\mathrm{Nd}$ reached $95 \%$. High melting point of $\mathrm{Nd}(1293 \mathrm{~K})$ made it difficult to dissolve in magnesium alloy at the melting temperature used in the experiment. But from $\mathrm{Mg}-\mathrm{Nd}$ binary phase diagram it can be seen that the eutectic point of $\mathrm{Mg}-\mathrm{Nd}$ alloy is lower than the melting point of $\mathrm{Mg}$, proving the probability of the formation of $\mathrm{Mg}-\mathrm{Nd}$ compound at melting temperature.

As the AZ31 magnesium alloy used in the present experiment was prepared under the protection of the flux, the existence of gas or inclusion was inevitable. However, adding trace elements into the alloy by low vacuum melting prevented the formation of new oxide, and moreover, brought more complete degasification and decomposition of gaseous compositions. It was reported ${ }^{[5]}$ that during vacuum melting, the solubility of diatomic gas in metal is directly proportional to the square root of its partial pressure in gas phase, for example:

$$
H=K_{\mathrm{H}_{2}} \sqrt{P_{\mathrm{H}_{2}}}
$$

where $H$ is referred to the solubility of hydrogen in alloy; $K_{\mathrm{H}_{2}}$ is referred to equilibrium coefficient of the hydrogen dissolving in metal, which is constant at constant temperature; $P_{\mathrm{H}_{2}}$ is referred to the partial pressure of hydrogen in gas phase. At the melting temperature, the higher the vacuity is, the lower the $P_{\mathrm{H}_{2}}$ is, and the less the residuum of hydrogen in alloy is. In the present experiment, the vacuity was 10.13 $\mathrm{kPa}$, and the residuum of hydrogen in AZ31 was reduced during remelting and alloying.

In addition, vacuum melting is beneficial to the decomposition of nitride. The $\mathrm{Mg}_{3} \mathrm{~N}_{2}$ produced in the process $\begin{array}{lllllllll}o & f & p & r & e & p & a & r\end{array}$

Table1 Content of Nd in AZ31 magnesium alloy (wt \%)

\begin{tabular}{cccccccc}
\hline \multirow{2}{*}{ Sample No. } & \multicolumn{3}{c}{ Before melting } & & \multicolumn{3}{c}{ After melting } \\
\cline { 2 - 4 } \cline { 5 - 8 } & 1 & 2 & 3 & & 1 & 2 & 3 \\
\hline 1 (AZ31) & 0 & 0 & 0 & & 0 & 0 & 0 \\
2 (AZ31-0.6\% & 0.6 & 0.6 & 0.6 & & 0.571 & 0.570 & 0.571 \\
\hline
\end{tabular}

$\mathrm{Nd})$

ing AZ31 was decomposed during the remelting process, and the resultant $\mathrm{N}_{2}$ was discharged out, reducing inclusion in the alloy.

Oxygen existed in the form of $\mathrm{MgO}$ in $\mathrm{AZ3} 1$ magnesium alloy. It is well known that, at a certain temperature, if the vapor pressure of monoxide in a metal is higher than that of pure metal, the monoxide will volatilize prior to metal. Therefore, the lower vapor pressure of $\mathrm{MgO}$ compared with that of pure magnesium under vacuum conditions, indicated that the oxygen was not removed under this experiment condition. However, oxygen may be removed in the form of gaseous product, for example, the addition of carbon into AZ31 would remove oxygen in the form of $\mathrm{CO}$.

\subsection{Analysis on microstructures}

Fig.1 shows the microstructure of as-cast AZ31 magnesium alloy observed with metallographic microscope. As $\alpha-\mathrm{Mg}$ displayed the close-packed hexagonal structure, the alloy element was easy to incur imbalanced solidification and then to form divorced eutectic structure for its low solid solubility in matrix. The $\beta$ - $\mathrm{Mg}_{17} \mathrm{Al}_{12}$ phase in the eutectic structure distributed on the grain boundary of $\alpha-\mathrm{Mg}$. In Fig.1, it is showed that the as-cast microstructure of alloy consisted of the matrix $\alpha-\mathrm{Mg}$ and the $\beta-\mathrm{Mg}_{17} \mathrm{Al}_{12}$ distributed along grain boundary. The comparison of Fig.1a and $1 \mathrm{~b}$ shows that the as-cast microstructure with $\mathrm{Nd}$ addition was significantly refined compared with that without $\mathrm{Nd}$ addition.

The SEM images of studied alloys are shown in Fig.2. It can be seen that there was less white particle phase in Nd-free AZ31 alloy shown in Fig.2a. After adding Nd, more white particle phases appeared, as seen in Fig.2b; moreover, some white needle phase occurred in the alloy with $\mathrm{Nd}$ addition, which indicates that the addition of $\mathrm{Nd}$ resulted in the formation of new phase. The energy dispersive analysis (EDS) results of the white needle or particle phases are shown in Table 2. It can be seen that the content of $\mathrm{Nd}$ was very low in the matrix, while it was high in white needle and particle phase, showing that addition of $\mathrm{Nd}$ induced the formation of Al-Nd or Mg-Nd compounds.

As $\mathrm{Nd}$ is featured by active chemical property, $\mathrm{Mg}-\mathrm{Nd}$ or Al-Nd compounds are probably formed upon the addition of $\mathrm{Nd}$ into AZ31. The tendency of different elements to form compounds can be indicated from their difference in electro-

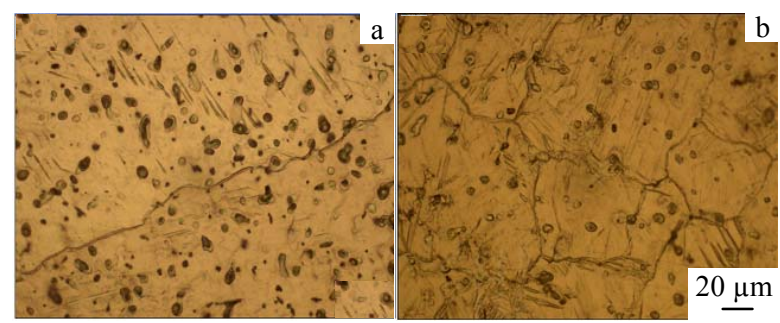

Fig.1 The microstructure of as-cast AZ31 magnesium alloy: 
(a) without $\mathrm{Nd}$ and (b) with $\mathrm{Nd}$

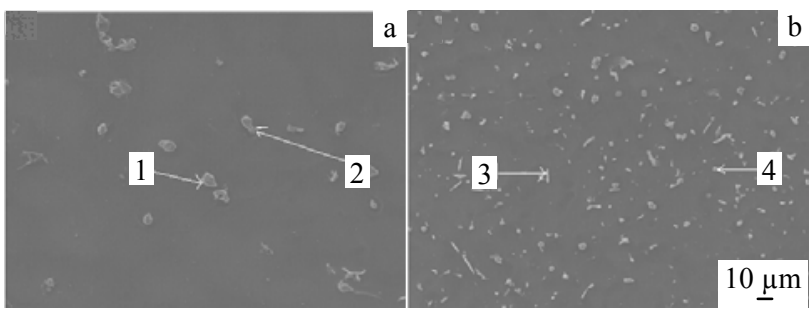

Fig.2 SEM images of as-cast AZ31 magnesium alloy:

(a) without $\mathrm{Nd}$ and (b) with $\mathrm{Nd}$

Table 2 Analysis results of EDS for the white phases in Fig.2 (wt\%)

\begin{tabular}{cccc}
\hline Position & $\mathrm{Mg}$ & $\mathrm{Al}$ & $\mathrm{Nd}$ \\
\hline 1 & 93.64 & 6.06 & \\
2 & 98.34 & 1.66 & \\
3 & 66.25 & 10.40 & 23.35 \\
4 & 87.52 & 3.20 & 9.28 \\
\hline
\end{tabular}

negativity. The bigger the difference of electro-negativity is, the stronger the bonding strength among the elements becomes, and the more easily the compounds can form ${ }^{[6]}$. As the difference of electro-negativity between $\mathrm{Nd}$ and $\mathrm{Al}$ is bigger than that between $\mathrm{Nd}$ and $\mathrm{Mg}$, $\mathrm{Nd}$ will combine preferentially with $\mathrm{Al}$ in $\mathrm{AZ31}$ alloy and form $\mathrm{Al}-\mathrm{Nd}$ compounds, which would consumed $\mathrm{Al}$ in AZ31 alloy and hinder the formation of $\mathrm{Mg}_{17} \mathrm{Al}_{12}$ phase, resulting in decreasing the size and the quantity of $\mathrm{Mg}_{17} \mathrm{Al}_{12}$ phase.

According to the Al-Nd binary phase diagram ${ }^{[7]}$, the combination of $\mathrm{Al}$ and $\mathrm{Nd}$ may form the compounds $\mathrm{Al}_{2} \mathrm{Nd}$, $\mathrm{Al}_{11} \mathrm{~d}_{3}$ and $\mathrm{Al}_{3} \mathrm{Nd}$. $\mathrm{Mg}$ is miscible with $\mathrm{Nd}$ in liquid phase, forming compounds $\mathrm{Mg}_{12} \mathrm{Nd}, \mathrm{Mg}_{3} \mathrm{Nd}$ and $\mathrm{MgNd}$. As a result, the needle and particle phases in Fig. $2 \mathrm{~b}$ are suggested to contain Al-Nd and $\mathrm{Mg}-\mathrm{Nd}$ compounds.

In order to further identify the composition phases in alloy, the X-ray diffraction analysis was adopted. The XRD patterns of the as-cast AZ31 magnesium alloy are shown in Fig.3.

The three strongest peaks were selected to calculate the $d$ value; the planar interval of corresponding phase, and the relative intensity of each diffraction peak was estimated. All the results were in good agreement with those of $\alpha-\mathrm{Mg}$, which means that the basic phase of as-cast AZ31 magnesium alloy was $\alpha-\mathrm{Mg}$ with hexagonal structure. Furthermore, in Fig.3a, the peaks with weak diffraction intensity were also observed, which were attributed to $\beta-\mathrm{Mg}_{17} \mathrm{Al}_{12}$ by calculating the correspondence $d$ values. In Fig.3b, along with the corresponding peaks of $\alpha-\mathrm{Mg}$ and $\beta-\mathrm{Mg}_{17} \mathrm{Al}_{12}$, there were diffraction peaks for $\mathrm{Al}_{2} \mathrm{Nd}$ and $\mathrm{Mg}_{12} \mathrm{Nd}$, which confirmed the statement mentioned above, that is, $\mathrm{Al}_{2} \mathrm{Nd}$ and $\mathrm{Mg}_{12} \mathrm{Nd}$ were formed upon the addition of $\mathrm{Nd}$ into AZ31.

\subsection{Mechanical Properties}

Fig.4 shows tensile force-displacement curve in the present experiment, and Fig.5 shows the tensile property of as-cast AZ31 alloy. It can be seen that the tensile strength, yield strength and percentage elongation of as-cast AZ31 alloy with Nd were 245, $171 \mathrm{MPa}$ and 9\%, respectively.

The addition of $\mathrm{Nd}$ into magnesium alloy formed $\mathrm{Al}_{2} \mathrm{Nd}$ compound and captured the $\mathrm{Al}$ in $\mathrm{AZ31}$, resulting in hindering the formation of $\mathrm{Mg}_{17} \mathrm{Al}_{12}$ phase, reducing its size and quantity, increasing the opportunity of heterogeneous nucleation and promoting the formation of new nucleus ${ }^{[8]}$. In addition, $\mathrm{Al}_{2} \mathrm{Nd}$ and $\mathrm{Mg}_{12} \mathrm{Nd}$ formed during alloy solidification can act as the nucleation additive for alloy solidification to promote the formation of new nucleus, so as to refine the as-cast structure of alloy and obviously improve the mechanical properties. According to the formula of Hall-Petch ${ }^{[9]}$, the yield strength of

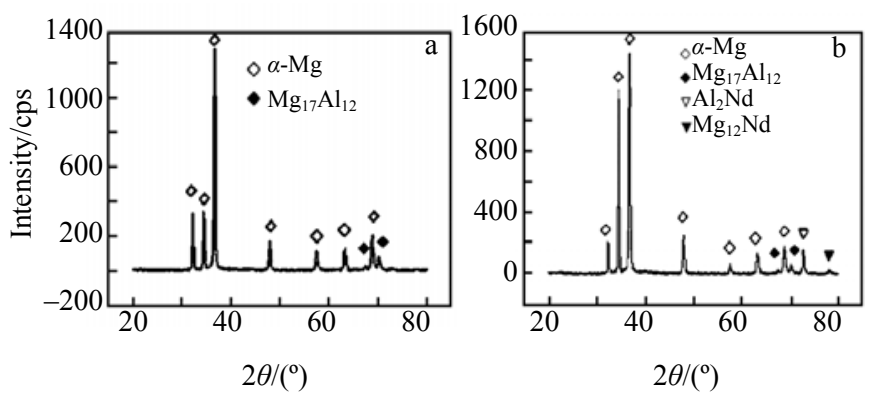

Fig.3 XRD patterns of as-cast AZ31 alloy: (a) without $\mathrm{Nd}$ and (b) with $\mathrm{Nd}$

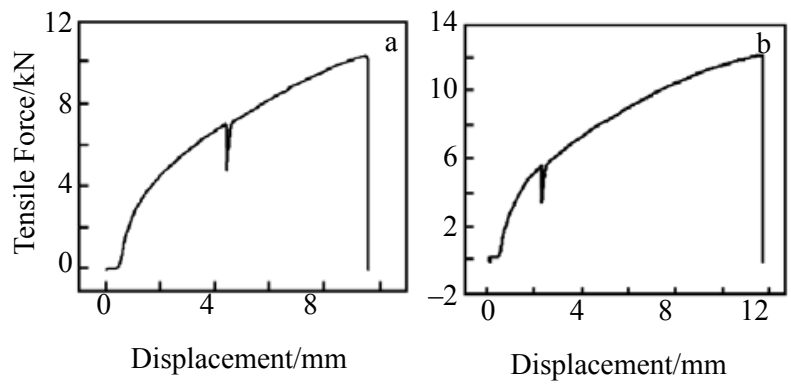

Fig.4 Tensile force-displacement curve in present experiment: (a) without $\mathrm{Nd}$ and (b) with $\mathrm{Nd}$

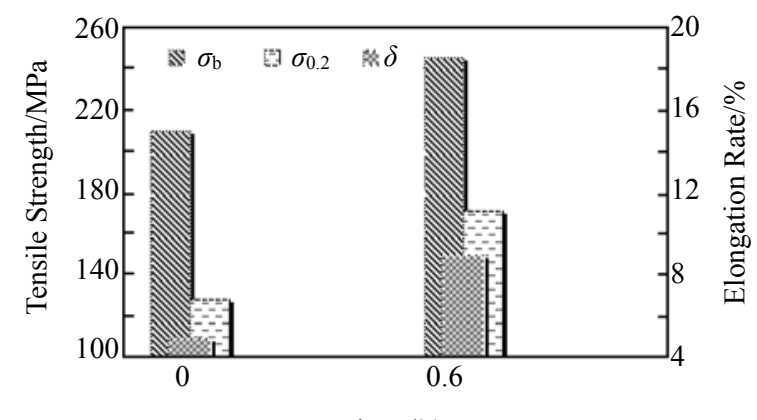

$\mathrm{Nd}, \mathrm{wt} / \%$ 
Fig.5 Tensile properties of as-cast AZ31 alloy

material is direct proportional to square root of grain size and the Taylor coefficient. As magnesium is of close-packed hexagonal structure, its slip ratio is small and Taylor coefficient is large, so the grain refinement greatly improved the alloy strength.

In brief, the mechanical properties of AZ31 magnesium alloy were improved by the effect of grain refinement strengthing, solution strengthening and precipitation strengthening of Nd.

\section{Conclusions}

The content of Nd added in AZ31 alloy could result in the formation of intermetallic compounds of $\mathrm{Al}_{2} \mathrm{Nd}$ and $\mathrm{Mg}_{12} \mathrm{Nd}$ at grain boundary and in $\alpha-\mathrm{Mg}$ matrix, and the absorption rate of $\mathrm{Nd}$ reached $95 \%$, which obviously refined AZ31 alloy microstructure and further improved mechanical properties. The AZ31 alloy containing Nd showed a tensile strength of $245 \mathrm{MPa}$, a yield strength of $171 \mathrm{MPa}$ and a elongation of $9 \%$.

\section{References}

1 Benedyk, Joseph C. Light Metal Age[J], 2005, 63: 36

2 Yan Jiuchun, Xu Zhiwu, Li Zhiyuan et al. Trans Nonferrous Met Soc China [J], 2005, 15: 21

3 Huang Xiaofeng(黄晓峰) et al. Rare Metal Materials and Engineering(稀有金属材料与工程)[J], 2005, 34(5): 795

4 Liu Shengfa(刘生发) et al. The Chinese Journal of Nonferrous Metals(中国有色金属学报)[J], 2006, 16(3): 464

5 Dai Yongnian(戴永年). Vacuum-Metallurgy of Non-Ferrous Metals Materials(有色金属材料的真空冶金)[M]. Beijing: Metallurgy Industry Press, 2003: 354

6 Yang Ping, Zhao Zude, Ren Xueping et al. J Mater Sci Technol[J], 2005, 21: 331

$7 \mathrm{Xu}$ Guangxian( 徐光年). Rare Earth( 稀土)[M]. Beijing: Metallurgy Industry Press, 1995: 386

8 Xu Yue(徐 越) et al. Journal of Rare Earths(稀土)[J], 2005, 23(5): 555

9 Alok Singh, Watanabe M, Kato A. Materials Science and Engineering $A[\mathrm{~J}], 2004,385: 382$

\title{
Nd 对 AZ31 镁合金微观组织与力学性能的影响
}

\author{
李明照, 李 琮, 刘旭光, 许并社 \\ (太原理工大学 教育部新材料界面与工程重点实验室, 山西 太原 030024)
}

\begin{abstract}
摘 要: 研究了 $\mathrm{Nd}$ 对 AZ31 镁合金微观组织和力学性能的影响。结果表明: $\mathrm{Nd}$ 在 AZ31 合金中的吸收率达 $95 \%, \mathrm{Nd}$ 加入 AZ31 合金 中形成了 $\mathrm{Al}_{2} \mathrm{Nd}$ 和 $\mathrm{Mg}_{12} \mathrm{Nd}$ 金属间化合物, $\mathrm{Nd}$ 使合金的平均晶粒尺寸减小，力学性能提高。含 $\mathrm{Nd}$ 的 $\mathrm{AZ} 31$ 合金铸态抗拉强度、屈服强 度和伸长率值分别为 $245 \mathrm{MPa} 、 171 \mathrm{MPa}$ 和 $9 \%$ 。
\end{abstract}

关键词: 镁合金; 钕; 微观组织; 力学性能

作者简介: 李明照, 女, 1956 年生, 博士, 副教授, 太原理工大学材料科学与工程学院, 山西 太原 030024, 电话: 0351-6010311 